\title{
Dynamic characteristics of pumped storage unit based on the full-size converter
}

\author{
He Wang ${ }^{1}$, Zhijie $\mathrm{Ma}^{2,1^{*}}$ \\ ${ }^{1}$ China Institute of Water Resources and Hydropower Research, 100038 Beijing, China \\ ${ }^{2}$ School of Electrical and Information Engineering, Tianjin University, 300072 Tianjin, China
}

\begin{abstract}
For enhancing the regulation performance and the efficient operation of the pumped storage power plant, this paper proposed to combine a hydro-generator set with a full-size converter to achieve the decoupling control of the machine and the power grid. On the basis of the model test, the regulation characteristics of a certain pump-turbine had been discussed and the implication for the converter was highlighted. At the same time, modeling and control for the machine side converter were presented, the simulation results showed that the hydroelectric generator system based on a full-size converter could track the torque change properly through the control system and achieve variable-speed operation due to the decoupling from the fixed grid frequency. The analysis revealed that it is possible to operate the plant beneficially by adopting a full-size converter between the generator motor and the power grid to improve the dynamic performance of the system effectively.
\end{abstract}

\section{Introduction}

With the gradual maturity of new energy sources such as wind power and photovoltaic power generation technology, a large number of power generation systems with large randomness and strong volatility are connected to the power grid. This type of input electrical energy usually has an adverse effect on the stability of the grid. Therefore, it is often necessary to equip energy storage devices to stabilize its transmission demand. As one of the most effective energy storage methods, pumped storage power stations can be used to stabilize load fluctuations and adjust the frequency of distributed energy systems. The regulating capacity has become an important indicator to measure the stability of the energy system of pumped storage units.[1-3]

Since the variable speed technology was used for wind generators to maximize its operating efficiency against the stochastic nature of wind energy, pumped storage units have also carried out such research. A study has been conducted for the Kadamparai pumped storage plant located in the state of Tamil Nadu, India, which can be operated as variable speed machines by adopting static frequency converters between stator and grid supply [4], and the direct power control strategy was investigated to approach the better dynamic performance in reference [5], the results using the algorithm indicate better performance of the PI controller to reduce the ripples of the active and reactive power of the stator as well as the harmonic power. The modeling, control, and operation range of variable speed pump-storage units are all reflected in references [68]. With further research of unit regulation technology, this paper aims at highlighting the control strategy of the unit and dynamic performance of step response based on a fullsize converter whose structure can be seen in Fig.1, the simulation results and optimization process are presented to pave the way for the variable-speed technology.

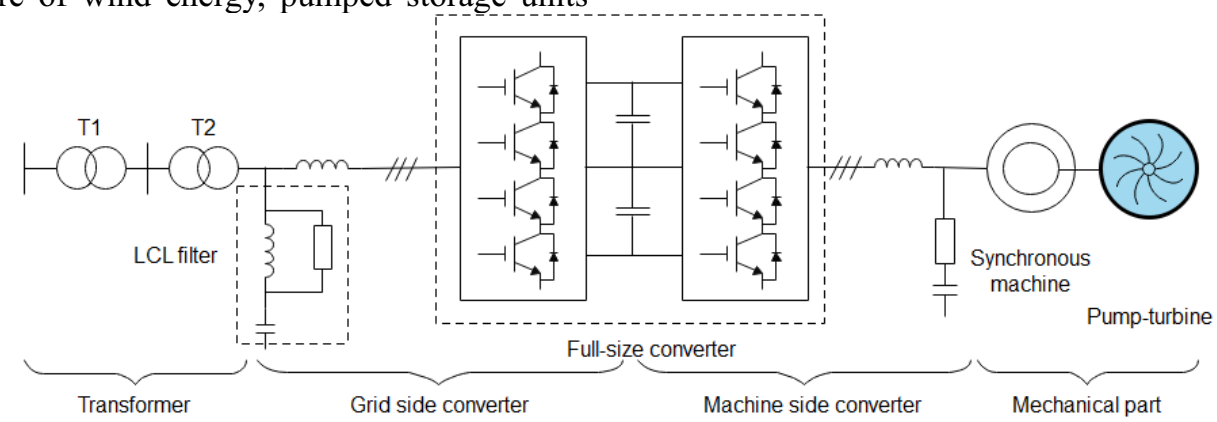

Fig. 1. The structure of unit based on full-size converter

\footnotetext{
*Corresponding author: mazj@iwhr.com
} 


\section{Operating characteristics of pump- turbine}

Pump-turbine is the most core mechanical power element in hydroelectric generating units. After decades of development, the design and optimization technology of hydraulic turbine have been studied deeply, a series of characteristic curves have been used to extract the operating status of the turbine for various head, discharge, power, and other parameters. This section mainly discusses the regulation characteristics of pump-turbine, taking two working states of pumping and power generation as the research object respectively to observe the external characteristics and the energy transmission results.

\subsection{Description of regulation ability}

Combining the converter and the corresponding control system, the power regulation capability of the turbine and generator can achieve variable-speed operation by controlling the frequency of the rotor circuit, the principle is shown in formula (1). From the perspective of the stator, the unit works at a constant synchronous speed, thereby realizing the speed regulation of the unit.

$$
n_{S}=n_{r}+60 f_{r} / p
$$

Where $n_{S}$ is the synchronous speed; $n_{r}$ is the rotor mechanical speed; $f_{r}$ is the excitation current frequency; $p$ is the number of pole pairs of the generator motor.

The power of the pump-turbine in two operating states can be expressed as:

$$
\left\{\begin{array}{c}
P_{t}=9.81 Q_{t} H_{t} \eta_{t} \\
P_{p}=9.81 \frac{Q_{p} H_{p}}{\eta_{p}}
\end{array}\right.
$$

Here, $P 、 Q$ and $\eta$ represent the power, discharge, head and efficiency of the pump-turbine respectively, and the subscript indicates its working condition.

\subsection{Optimization of the four-quadrant characteristic curve}

According to the investigated case of this study, it could be noticed that the curve of pump-turbine has crossed and overlapped in the first and fourth quadrants, which exhibit a typical S-shaped curve, leading to numerical troubles and unclear calculations during the hydraulic transition process.

To circumvent this problem, the method of Sutertransformation is applied for this section, making the curve transform into two groups of periodic variation curves, namely the $W H(x, y)$ and $W B(x, y)$, see formula (3) for the form.

$$
\left\{\begin{array}{c}
x=\arctan \left(\frac{Q_{11} / Q_{11 r}}{N_{11} / n_{11 r}}\right) \\
W H(x, y)=\frac{1}{\left(N_{11} / N_{11 r}\right)^{2}+\left(Q_{11} / Q_{11 r}\right)^{2}} \\
W B(x, y)=\frac{M_{11} / M_{11 r}}{\left(N_{11} / N_{11 r}\right)^{2}+\left(Q_{11} / Q_{11 r}\right)^{2}}
\end{array}\right.
$$

Where $y$ is the guide vane opening; $N_{11}, Q_{11}$ and $M_{11}$ stand for the unit speed, unit discharged and unit torque respectively; The subscript $\mathrm{r}$ represents reference and benchmark values, where the rated parameters of pump-turbine are taken in this case.

The conversion can be expressed as:

$$
\left(N_{11}, Q_{11}, M_{11}, y\right) \rightarrow(W H, W B, x, y)
$$

Taking the JFP1252A pump-turbine as an example, its model parameters are shown in Table 1.

Table 1. Model characteristics of the pump-turbine

\begin{tabular}{ccc} 
Parameter & Value & Unit \\
\hline $\mathrm{Nm}$ & 1200 & $\mathrm{rpm}$ \\
$\mathrm{Qm}$ & 0.22 & $\mathrm{~m}^{3} / \mathrm{s}$ \\
$\mathrm{Hm}$ & 30.12 & $\mathrm{~m}$ \\
$\mathrm{Tm}$ & 578.41 & $\mathrm{~N} \cdot \mathrm{m}$ \\
$\mathrm{D} 1 \mathrm{~m}$ & 0.26 & $\mathrm{~m}$ \\
\hline
\end{tabular}

As you can see in Fig.2, two three-dimensional surfaces were achieved containing the complete characteristic curves of pump-turbine. According to the calculation of the characteristic curves of the reducedscale model, it's obvious to find that the unit speed can be changed from $77 \mathrm{r} / \mathrm{min}$ to $92 \mathrm{r} / \mathrm{min}$ during the guide vane opening range $0.3 \sim 1.0$, the efficiency of the unit will maintain over $88 \%$ consistently during the speed adjustment process. These index parameters indicate that the variable-speed hydroelectric generator set can be operated efficiently and stably while having a certain range of adjustment ability as expected.
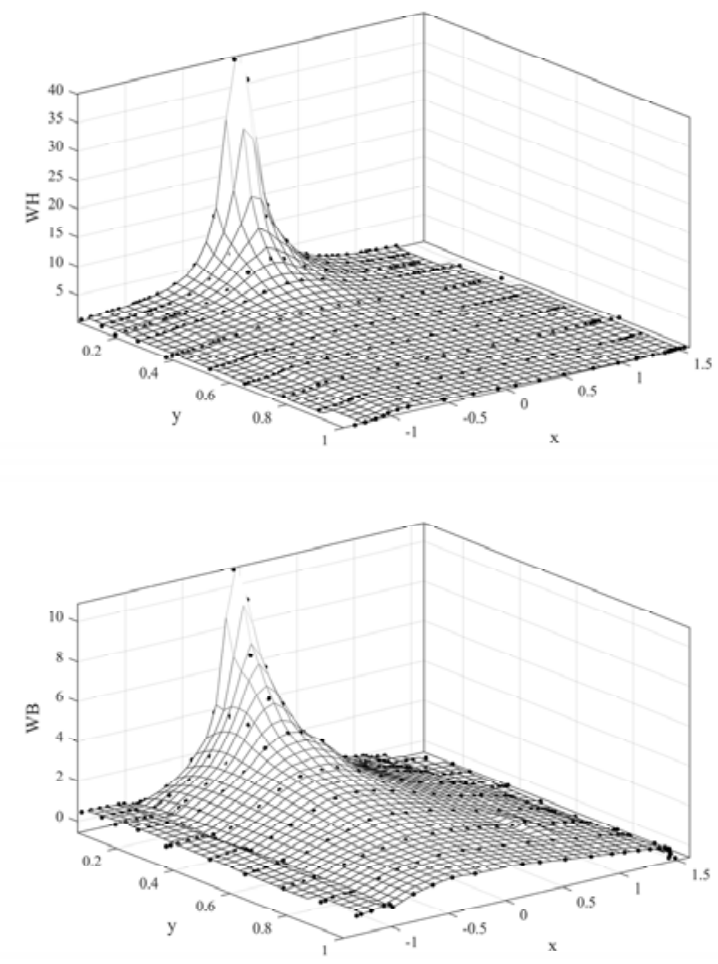

Fig. 2. Transformed maps $W H$ and $W B$ (represented as surfaces) 


\section{Control strategy}

According to the load analysis and working characteristics of the pump-turbine in two operating states, a power response control strategy for pumped storage units was proposed in which the power is regulated by the excitation, speed, and guide vane opening are controlled by the governor. The control block diagram is shown in Fig.3. As you can see, the rotor speed is controlled by the wicket gate position of the turbine, and the real power is controlled by the control loop of the converter. This procedure is repeated for a number of different conditions such that efficiency can be expressed as a function of the power, the head, and the speed.[9]

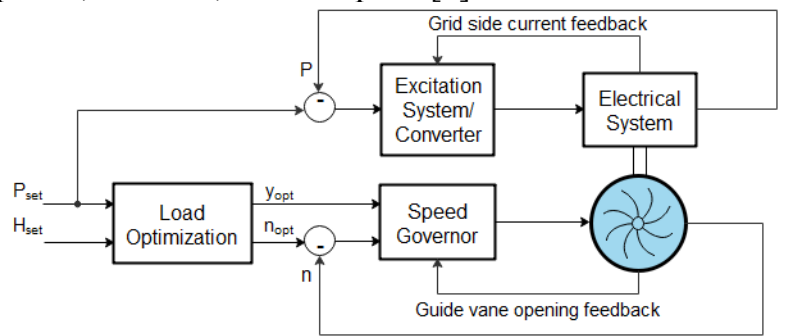

Fig. 3. Control strategy of unit

The block of load optimization shown in Fig.3 refers to the procedure of the optimal speed and the optimal guide vane opening, which will be described in detail next. To improve the operating efficiency of the turbine, when the speed of the unit changes, it should be managed that the turbine always runs along the optimal efficiency trajectory. The state equation of the turbine is expressed as formula (5).

$$
\left\{\begin{array}{c}
H=\left(\frac{Q}{y}\right)^{2} \\
P=9.81 Q H \eta \\
\dot{y}=k_{a}\left(u_{s}-y\right) \\
\dot{Q}=\frac{1}{T_{w}}\left(1-\frac{Q^{2}}{A_{t}^{2} y^{2}}\right)
\end{array}\right.
$$

Where $k_{a} 、 u_{s}$ are the electromechanical time constant and the input voltage; $A_{t} 、 T_{w}$ are the guide vane coefficient and the water inertia time constant respectively.

For generating mode, the speed of the unit is controlled by the electro-hydraulic converter, where the hydraulic turbine obtains $\mathrm{n}_{\mathrm{opt}}$ through speed optimization calculation according to the given value $\mathrm{P}_{\text {set }}$ and $\mathrm{H}_{\text {set }}$, the optimal efficiency operation will be achieved conforming to the governor and excitation current frequency. The speed signal is converted into a guide vane adjustment signal after passing through the governor, and then the flow is adjusted by controlling the servomotor switch to realize the adjustment of the unit speed. Moreover, the corresponding optimal guide vane opening can be determined due to the flow-head function and efficiency characteristic curve for pumping mode, and the dynamic process of the mechanical guide vane is the same as mentioned before, the specific load optimization flowchart has shown in Fig.4.

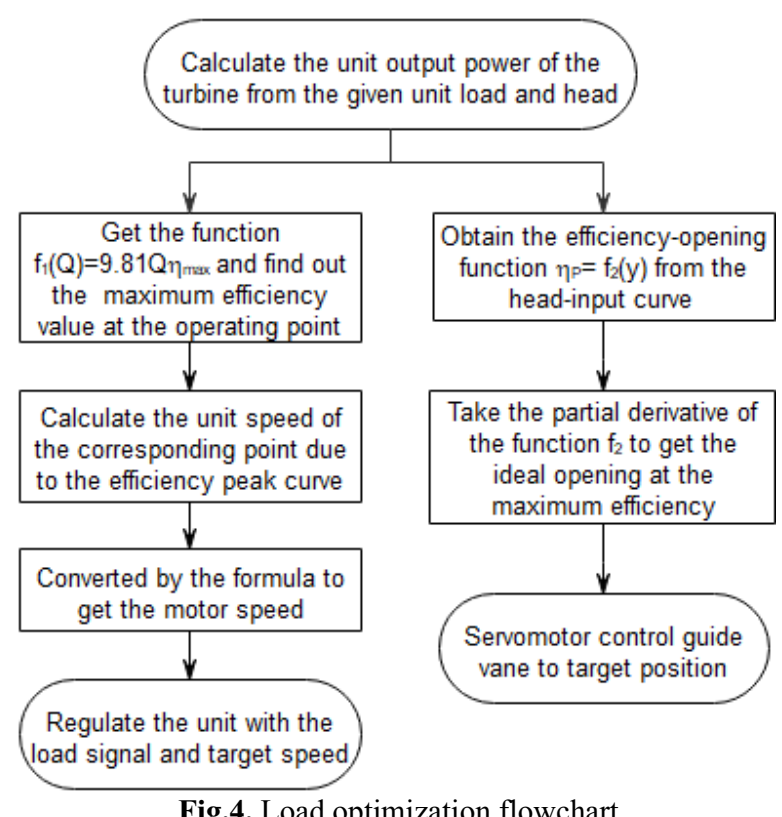

\section{Simulation and results}

For considering the dynamic behavior of converter and generator motor system, a model (discrete mode) in MATLAB/Simulink was adopted to construct simulations under several conditions.

\subsection{Description of the system}

From the structure diagram of the full-size converter pumped storage unit in Fig.1, it could be seen that the synchronous motor is connected to the machine-side converter. Use vector control for the generator-side converter, and the parameters of system simulation were setting as follows: Rated voltage of synchronous machine as $3.3 \mathrm{kV}$, rated frequency as $50 \mathrm{~Hz}$, pole pair number as 6 . To reduce the simulation time, artificially reduce the rotor inertia to $10 \mathrm{kgm}^{2}$.

Assuming the model as: Ignore the influence of changes in space harmonics, magnetic saturation, core loss, and temperature on winding resistance. The generator-side converter receives the active power command and adjusts the corresponding parameters through vector control. Here, the power direction is set to be negative for pumping mode. Conversely, the power in the generating mode is positive.

\subsection{Analysis of results}

The dynamic performances of a 5 MW unit were investigated by the simulation of the model in case of change of torque and DC bus voltage. Take power generation conditions as an example to verify the torque tracking performance of the motor, the rotor speed was given as $1000 \mathrm{r} / \mathrm{min}$, and a three-stage load was set (The torque step signal $\mathrm{Te}=25000 \mathrm{~N} \cdot \mathrm{m}$ is connected after $0.5 \mathrm{~s}$, and the command changes to $20000 \mathrm{~N} \cdot \mathrm{m}$ after $1 \mathrm{~s}$ ). The simulation results displayed in Fig. 5 and Fig. 6 show the changes in rotor speed, stator current, electromagnetic torque, and DC voltage with time respectively, combined 
with the q-axis current curve in Fig.5, it can be concluded that the stator current decoupling result and the torque dynamic tracking effect are ideal. Similarly, keep the motor speed at $1000 \mathrm{r} / \mathrm{min}$ and the initial DC bus voltage command value of $5200 \mathrm{~V}$, as to study the response performances of the DC bus voltage control, change the DC bus voltage value after $1.5 \mathrm{~s}$, the corresponding bus voltage response are shown in Fig.6, It can be seen that the DC bus voltage can quickly return to a stable value through the control of the outer loop of converter after a step change, which indicates that the active power of the unit can be adjusted by running at a constant DC voltage. Fig.7 shows the effect of stator current dynamic tracking, namely the dynamic process of torque tracking.
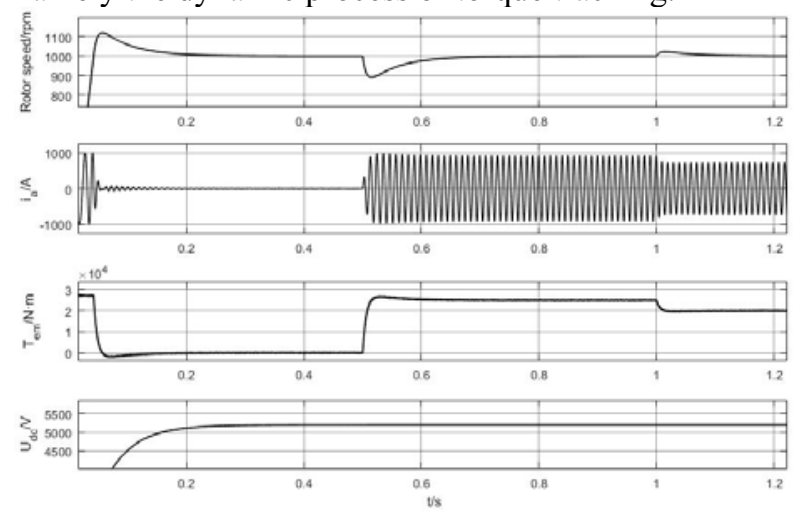

Fig. 5. Load response
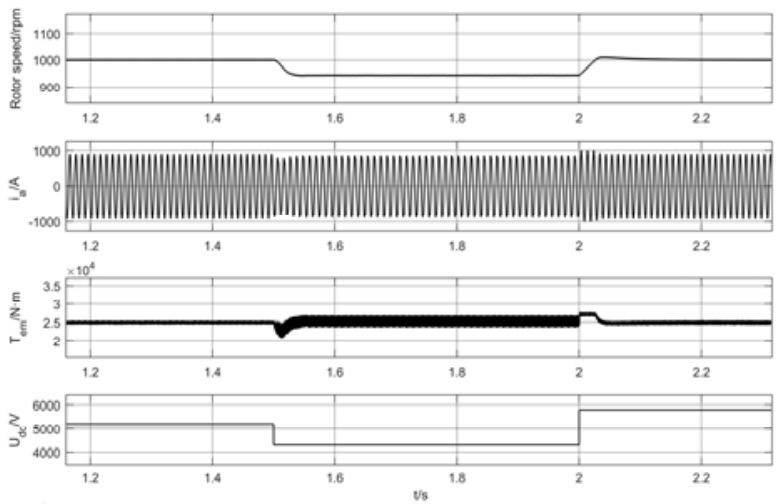

Fig. 6. DC side voltage mutation response

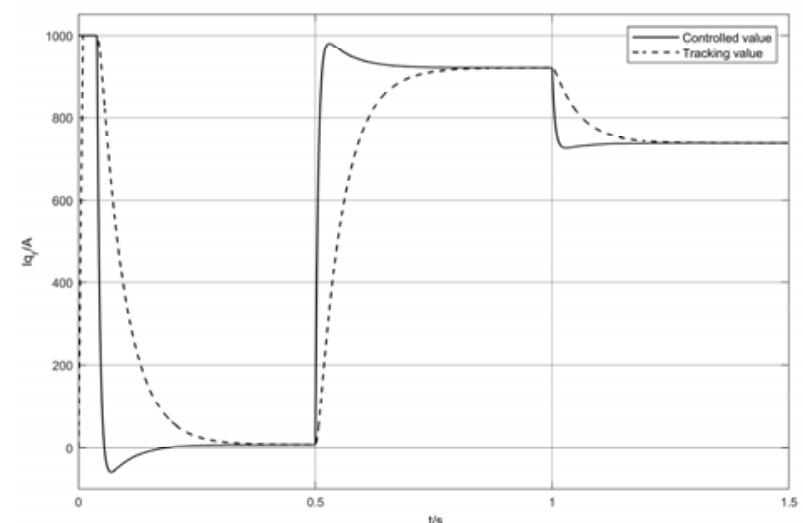

Fig.7. Q-axis current tracking curve of load change

\section{Conclusion}

This paper analyzed the characteristics of the hydraulic machinery and electrical system of a pumped storage unit based on full-size converter technology. The dynamic characteristics were described by taking a 5MW unit as an example. A control strategy based on the characteristic curve of the turbine as the basis for load optimization and the reference value of power and head was proposed. The traditional hydroelectric unit was connected to an electronic component converter, which realizes the efficient operation of the pump-turbine while decoupling the stator current, also, enhance the reliability of the pumped storage power station in the multi-energy complementary energy system. In summary, it can be concluded that the full-size converter can play a certain regulatory role in the hydropower system, and achieve great tracking control in the system.

As far as the model test in this article is concerned, for generating mode, the speed range of the turbine can be calculated from 0.824 p.u. to 1.094 p.u., the power range is between 0.71 p.u. to 1.26 p.u.; For pumping mode, the rotational speed can be changed from 0.990 p.u. to 1.041 p.u., the system could produce a power adjustment range of 0.184 p.u. at the highest head and 0.24 p.u. at the lowest. It is worth mentioning that, as a kind of reliable electronic control components, converters can not only be used in newly constructed hydropower stations but also can be retrofitted for some existing pumped storage power stations. The adjustment capabilities of hydropower will be further strengthened, which provides a new path for the grid support.

\section{References}

1. Sperstad IB, Degefa MZ, Kjølle G. The impact of flexible resources in distribution systems on the security of electricity supply: A literature review. Electric Power Systems Research. 2020;188.

2. Rahmati I, Akbari Foroud A. Pumped-storage units to address spinning reserve concerns in the grids with high wind penetration. Journal of Energy Storage. 2020;31.

3. Javed MS, Zhong D, Ma T, Song A, Ahmed S. Hybrid pumped hydro and battery storage for renewable energy based power supply system. Applied Energy. 2020;257.

4. Sivakumar N, Das D, Padhy NP. Variable speed operation of reversible pump-turbines at Kadamparai pumped storage plant - A case study. Energy Conversion and Management. 2014;78:96-104.

5. Hosseini SMH, Rezvani A. Modeling and simulation to optimize direct power control of DFIG in variablespeed pumped-storage power plant using teachinglearning-based optimization technique. Soft Computing. 2020.

6. Nicolet C, Braun O, Ruchonnet N, Hell J, Béguin A, Avellan F. Simulation of pump-turbine prototype fast mode transition for grid stability support. Journal of 
Physics: Conference Series. 2017;813.

7. Mercier T, Olivier M, Dejaeger E. Operation ranges and dynamic capabilities of variable-speed pumpedstorage hydropower. Journal of Physics: Conference Series. 2017;813.

8. Béguin A, Nicolet C, Hell J, Moreira C. Assessment of power step performances of variable speed pumpturbine unit by means of hydro-electrical system simulation. Journal of Physics: Conference Series. $2017 ; 813$.

9. Pannatier Y, Kawkabani B, Nicolet C, Simond J-J, Schwery A, Allenbach P. Investigation of Control Strategies for Variable-Speed Pump-Turbine Units by Using a Simplified Model of the Converters. IEEE Transactions on Industrial Electronics. 2010;57:303949. 